\title{
Gaps in Medical and Device Therapy for Patients with Left Ventricular Systolic Dysfunction: The EchoGap Study
}

\author{
Hisham Dokainish*, Lauren Jewett, Robby Nieuwlaat, Joshua Coulson, Catherine Demers, Eva Lonn, \\ Jeff Healey, Brian Haynes and Stuart Connolly
}

\author{
Division of Cardiology, Department of Medicine and the *Department of Epidemiology and Biostatistics, McMaster \\ University, Hamilton, Ontario, Canada
}

\begin{abstract}
Objectives: To assess gaps between guidelines and medicine prescription/dosing and referral for defibrillator therapy in patients with left ventricular systolic dysfunction (LVSD).

Methods: Outpatient echocardiography reports at an academic hospital centre were screened and outpatients with LVEF $<40 \%$ were included. A questionnaire was mailed to the patients' physician, querying prescription/dosing of ACEinhibitors (ACEi), angiotensin receptor blockers (ARB) and beta-blockers (BB). Patients with LVEF $<30 \%$ had additional questions on implantable cardiac defibrillator (ICD) referral.

Results: Mean age was 69.6+/-12.2 years and mean LVEF was 29.7+/-6.5\%. ACEi and/or ARB prescription rate was $260 / 309(84.1 \%$ ) versus $256 / 308(83.1 \%$ ) for BB ( $p=$ NS for comparison). Of patients on ACEi, 77/183(42.1\%) were on target dose, compared to $7 / 45(15.5 \%)$ for $\mathrm{ARB}$ and $9 / 254(3.5 \%)$ for $\mathrm{BB}(\mathrm{p}<0.01)$. Of 171/309 patients $(55.3 \%)$ with $\mathrm{LVEF}<30 \%, 72 / 171(42.1 \%)$ had an ICD and 16/171(9.4\%) were referred for one.

Conclusion: Prescription rates of evidence-based HF medicines are relatively high in outpatients with LVSD referred for echocardiography at this Canadian academic medical centre; however, the proportion of patients at target doses was modest for ACEi and low for ARB and BB. Approximately half of patients who qualify for ICD by EF alone have one or were referred. Important reasons for patients with LVSD not on evidence-based therapy were identified.
\end{abstract}

Keywords: Echocardiography, Evidence-based Medicine, Left Ventricular Dysfunction, Heart Failure, Knowledge Translation, Treatment Gaps.

\section{INTRODUCTION}

Heart Failure (HF) has a high prevalence and is associated with substantial morbidity and mortality [1]. Although medical and device therapies have decreased the rate of hospitalizations and mortality,the prevalence and incidence of HF continue to increase [2, 3]. When used at recommended doses, medical therapies such as angiotensin converting enzyme inhibitors (ACEi), angiotensin receptor blockers (ARB), and beta blockers (BB) have been shown to decrease morbidity and mortality in patients with left ventricular systolic dysfunction (LVSD)and HF [2-18]. In addition, the use of implantable cardiac defibrillators (ICD) has been shown to decrease mortality in patients with LVSD [19-22]. The Canadian Cardiovascular Society (CCS) guidelines recommend prescription of these medications at the indicated target doses in patients with LV ejection fraction $<40 \%$, regardless of symptoms; in addition, the accepted threshold EF for consideration of ICD referral in

\footnotetext{
*Address correspondence to this author at the Department of Epidemiology and Biostatistics McMaster University, Echocardiography, Hamilton Health Sciences, 237 Barton St. E. CVSRI \#C3 111, Hamilton, ON, Canada L8L 2X2; Tel: 905-527-4322; Ext: 40327; Fax: 1-905-577-1424;

E-mail: hisham.dokainish@phri.ca
}

Canada is $<30 \%$ [5]. Prior studies have reported varying prescription rates of $\mathrm{ACEi} / \mathrm{ARB}$, and $\mathrm{BB}$ in patients with LVSD or HF [23-36]. Furthermore, a considerable portion of patients that have been prescribed ACEi/ARB and BB are on less-than-target doses which may diminish the benefits of these therapies in regards to HF morbidity and mortality [57, 33-36]. Likewise, while ICD implantation rates are increasing, there are some preliminary data suggesting gaps in referral rates for ICD in patients with LVSD [37-39]. Yet, the existence and potential size of gaps in prescription and dosing of HF medicines and referral for ICD in Canadian patients are not well described, and the reasons for these potential gaps are not well understood.

\section{METHODS}

The study protocol was approved by the Research Ethics Board of Hamilton Health Sciences. This was a retrospective study of outpatients referred for resting transthoracic echocardiography at Hamilton Health Sciences facilities between January 1, 2009 and December 31, 2010. The echocardiographic database was screened to identify all outof-hospital patients (outpatients) with $\mathrm{LVEF}<40 \%$, and a questionnaire was mailed to the physician who ordered the echocardiogram with patients $\mathrm{LVEF}<40 \%$. The 
questionnaire asked the referring physician questions about prescription of $\mathrm{ACEi}, \mathrm{ARB}$, and $\mathrm{BB}$ along with the dose prescribed. If an $\mathrm{ACEi}, \mathrm{ARB}$, or BB was not prescribed, the physician was asked to indicate the reason(s) for nonprescription. Target doses for all medications were acquired from CCS HF guidelines [5], with the exception of fosinopril, quinapril, and losartan which were obtained from American College of Cardiology/American Heart Association HF guidelines [6], as the CCS HF guidelines did not include target doses for these medications.

For patients with $\mathrm{EF}<30 \%$, physicians received an additional question regarding ICD referral,which also asked potential reasons in case of non-referral. Questionnaires were sent $>6$ months after the echocardiogram was performed to allow sufficient time for the referring physician to make a therapeutic decision based on the echocardiography results, and titrate medicines to target doses. Echocardiogram reports performed on hospital inpatients were excluded in this study as LV dysfunction in acutely ill hospital inpatients could be due to transitory causes (sepsis, electrolyte/renal/endocrine disturbance, acute ischemia, tachycardia) or other acute noncardiac issues which may impact decisions on medicine prescription and titration of doses as well as ICD referral.

All patient information and data were anonymized. The physician was asked to return the questionnaire by fax. If the questionnaire was not received after 10 days, a reminder was sent by facsimile the following day (day 11). Similarly, if the questionnaire was still outstanding, another reminder was sent after 21 days by facsimile, then at 36 days by telephone call. If after 56 days the questionnaire had not yet been received, a second copy of the entire questionnaire was mailed. Once received, data from the questionnaire was entered into the database. Patients were excluded from analysis if the referring physician failed to return the questionnaire, returned the questionnaire but did not complete it, or if the patient was reported as deceased since the time of echocardiogram, as current medications and doses were not available for deceased patients.

\section{Statistical Methods}

Continuous variables are reported as mean (standard deviation [SD]), and dichotomous variables are displayed as frequency (\%). Comparisons for continuous variables were tested with independent t-test, for nominal variables with chi-square test, and for ordinal variables with chi-square for trend (Gamma). These tests were conducted as two-sided tests with a confidence interval of $95 \%$, and $p$-value $<0.05$ was considered significant. Analyses were performed using SPSS for Windows v.14.0 (IBM, 2007).

\section{RESULTS}

Of the 4523 outpatient echocardiograms performed during the study period, $576(12.7 \%)$ were reported as having LVEF $<40 \%$. Therefore, 576 questionnaires were mailed to 352 referring physicians, of which 371/576 $(64.4 \%)$ were returned. In $51 / 371(13.7 \%)$ of patients, the questionnaires were returned stating that the patient had deceased since the echocardiogram was performed and these patients were excluded from analysis. Incomplete questionnaire were also excluded from analysis (13/371, $3.5 \%)$. Therefore 309/576 (54\%) questionnaires were analyzed. The mean age of the study population was 69.4 \pm 11.2 years (range $=38.5-89.4$ years), the mean LVEF was $29.9 \pm 6.4 \%$ and $230 / 309(74.4 \%)$ were male. $15 / 309$ (4.8\%) patients were on no medical therapy. Physicians answered questions regarding HF symptoms for 245/309 (79.3\%) of patients and 59/245 (24.1\%) patients were reported to have at least one HF symptom.

\section{Medicine Prescription Rates and Dosing}

Among 309 LVSD patients, 256 patients (83.1\%) were prescribed BB, compared to 190 for ACEi (61.5\%) and 73 for ARB (23.6\%); 260 patients (84.1\%) were on ACEi and/or ARB, and 3 patients were on both ACEi and ARB $(\mathrm{p}=\mathrm{NS}$ for $\mathrm{BB}$ vs. ACEi/ARB) (Table 1).The specific medication types and the proportions in which they are prescribed are shown in Figs. (1, 2 and 3), respectively. ACEi doses were most frequently at target dose (42.1\%), followed by ARB (15.5\%), and BB (3.5\%) (ACEi vs. ARB: $\mathrm{p}=0.000184 ;$ ACEi vs. BB: $\mathrm{p}<0.0001 ;$ ARB vs. BB: $\mathrm{p}<0.0001$, Table 2). The likelihood of a patient receiving medical or device therapy was not significantly different between those with and those without HF symptoms (Table 3).

Table 1. Medication prescription rates.

\begin{tabular}{|l|c|}
\hline \multicolumn{1}{|c|}{ Medication } & Prescription Rate N=309 \\
\hline \hline ACEI & $190(61.5 \%)$ \\
\hline ARB & $73(23.6 \%)$ \\
\hline ACEI and/or ARB & $260(84.1 \%)$ \\
\hline BB* & $256(83.1 \%)$ \\
\hline ACEI and BB & $159(51.6 \%)$ \\
\hline ARB and BB & $66(21.4 \%)$ \\
\hline ACEI /ARB and BB & $221(71.7 \%)$ \\
\hline
\end{tabular}

$\mathrm{ACEi}=$ angiotensin converting enzyme inhibitor; $\mathrm{ARB}=$ angiotensin receptor blocker; $\mathrm{BB}=$ beta blocker. ${ }^{*} \mathrm{p}<0.01$ for $\mathrm{BB}$ compared to $\mathrm{ACEi}$ or $\mathrm{ARB}$ alone; $\mathrm{p}=\mathrm{NS}$ for BB vs. ACEi and/or ARB. 


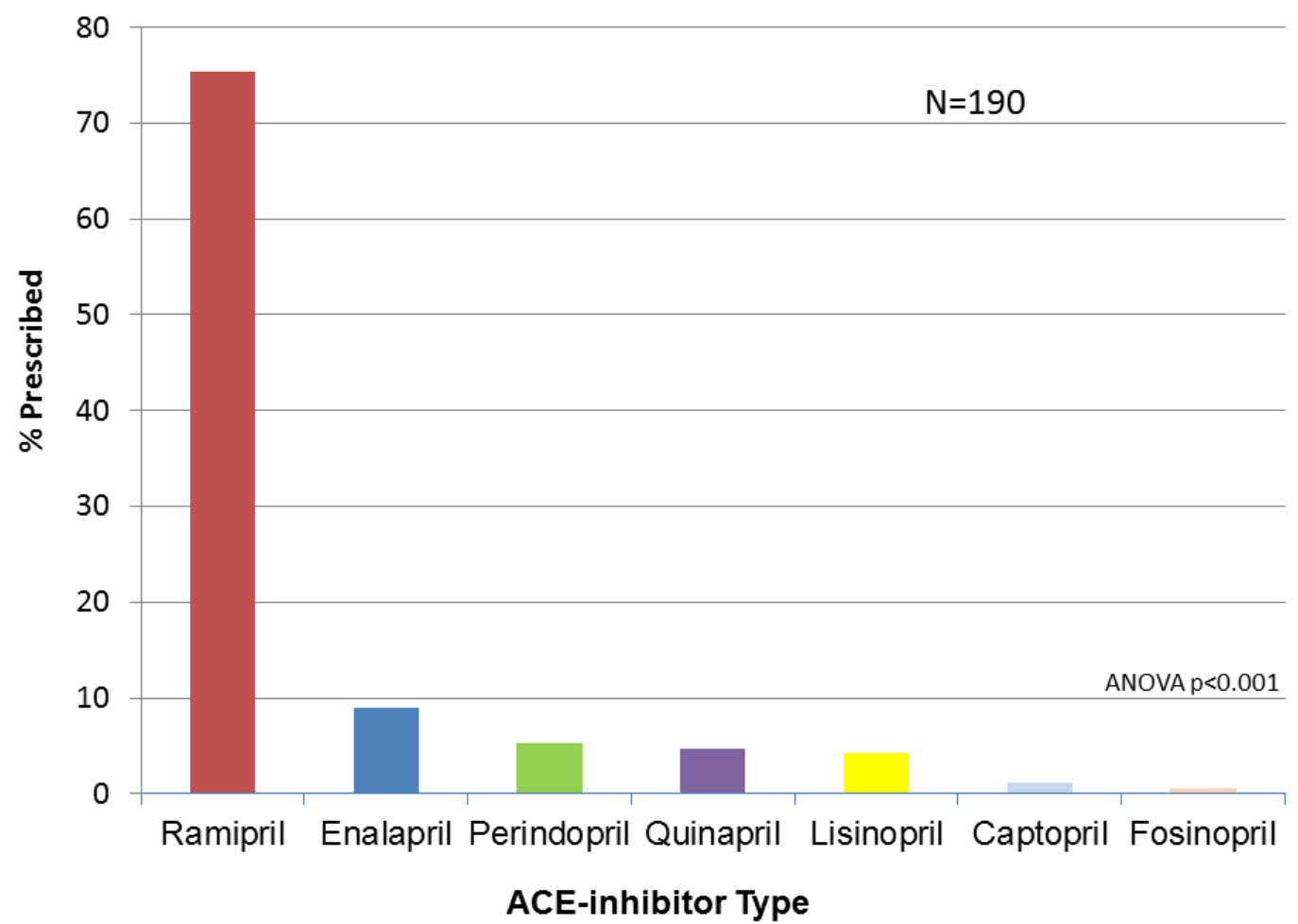

Fig. (1). Type of ACE-inhibitor Prescribed for the 190 Patients Prescribed ACE-Inhibitor. ACE=angiotensin converting enzyme.

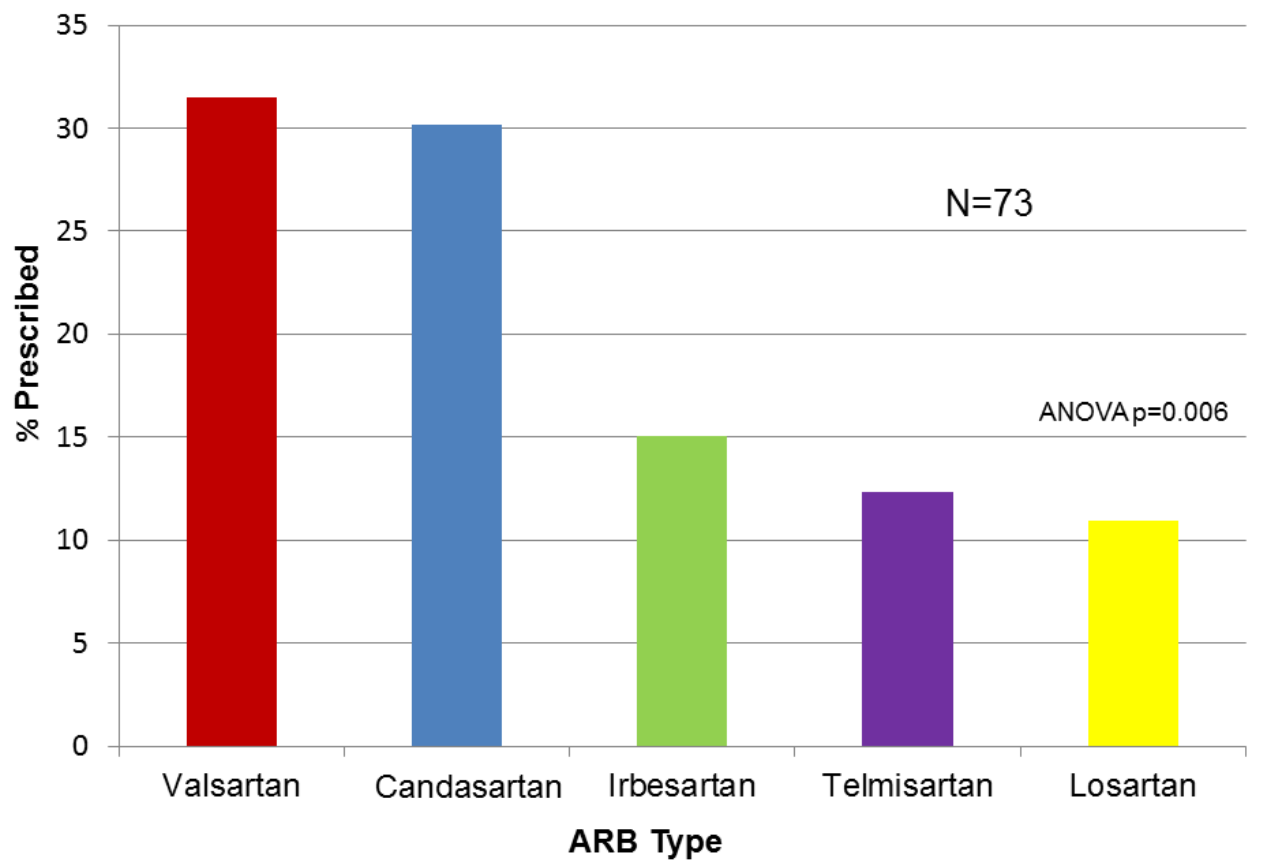

Fig. (2). Type of ARB-inhibitor Prescribed for the 73 Patients Prescribed ARB. ARB=angiotensin receptor blocker.

\section{Referral for ICD}

Of $173 / 309(56 \%)$ patients with $\mathrm{EF}<30 \%, 2 / 309(0.6 \%)$ did not have information about ICD referral complete on the questionnaire and were therefore excluded from analysis. Of the $171 / 309(55.3 \%)$ remaining patients with $\mathrm{LVEF}<30 \%$, $72 / 171(42.1 \%)$ already had an ICD implanted, and 16/171 $(9.4 \%)$ had been referred for an ICD. Therefore, 88/171 $(51.5 \%)$ patients identified as qualifying for an ICD (by EF criteria alone) had an ICD or were referred for one. Patients with $\mathrm{EF}<20 \%$ were numerically (but not statistically) more likely to be referred for or receive an ICD $(28 / 44,63.3 \%)$ compared to patients with an EF $21-30 \%$ (60/129, 46.5\%; $\mathrm{p}=0.061$ for comparison).

\section{Barriers to Medical and Device Therapy}

ACEi or ARB was not prescribed to $15.9 \%$ (49/309) of the study population. The most common reasons given by physicians for patients not on an ACEi/ARB were "renal dysfunction" (30\%), "cardiac function improved" (24\%) and "hypotension" (14\%, Fig. 4). For BB, 53/309 (17.1\%) of 


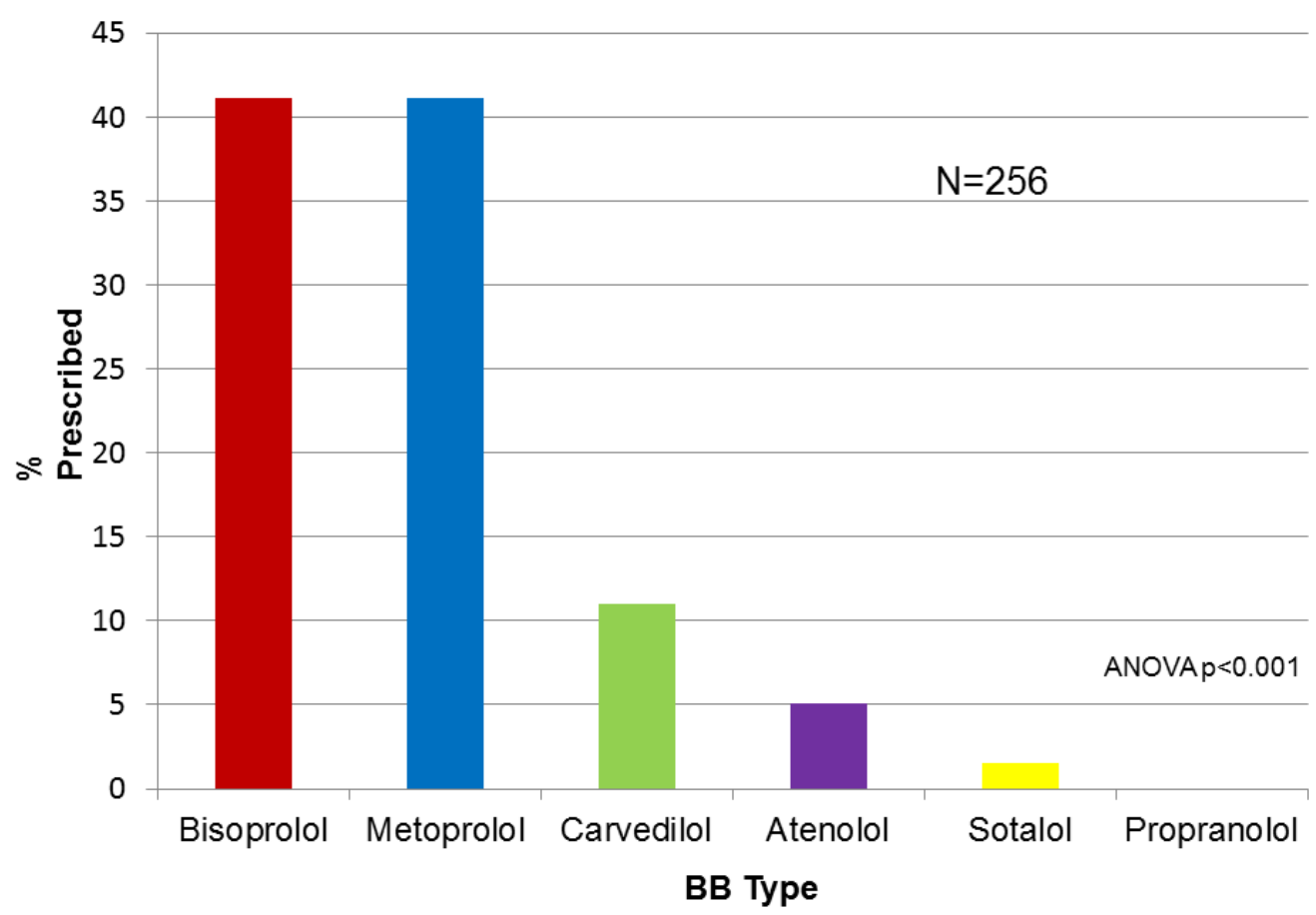

Fig. (3). Type of BB Prescribed for the 256 Patients Prescribed BB. BB=beta-blocker.

Table 2. Target dose rates according to medication type.

\begin{tabular}{|l|c|c|c|c|}
\hline & Dose & Below Target Dose & On Target Dose & Above Target Dose \\
\hline \hline \multirow{3}{*}{ Medication } & ACEI $(\mathrm{n}=183)$ & $93(50.8 \%)$ & $77(42.1 \%)$ & $13(7.1 \%)$ \\
\cline { 2 - 5 } & $\mathrm{ARB}(\mathrm{n}=45)$ & $38(84.4 \%)$ & $7(15.5 \%)$ & $0(0.0 \%)$ \\
\cline { 2 - 5 } & $\mathrm{BB}(\mathrm{n}=254)$ & $245(96.5 \%)$ & $9(3.5 \%)$ & $0(0.0 \%)$ \\
\hline
\end{tabular}

$\mathrm{ACEi}=$ angiotensin converting enzyme inhibitor; $\mathrm{ARB}=$ angiotensin receptor blocker; $\mathrm{BB}=$ beta blocker. $\mathrm{ACEi}$ vs $\mathrm{ARB}: \mathrm{p}=0.0002 ; \mathrm{ACEi}$ vs $\mathrm{BB}: \mathrm{p}<0.0001$; ARB vs BB: $p<0.0001$

Table 3. Medicine prescription rates according to heart failure symptom status.

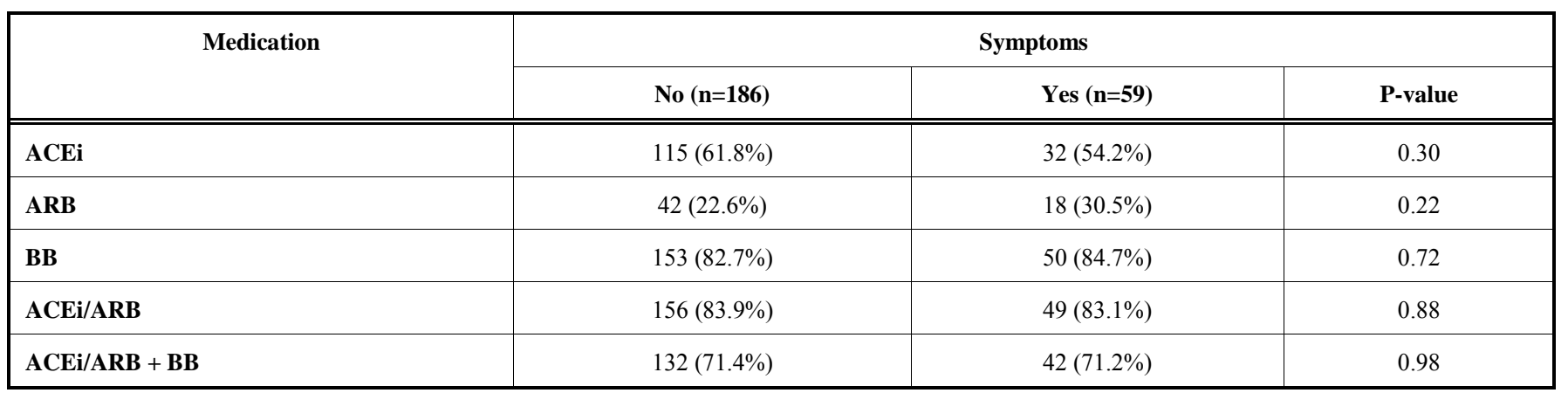

$\mathrm{ACEi}=$ angiotensin converting enzyme inhibitor; $\mathrm{ARB}=$ angiotensin receptor blocker; $\mathrm{BB}=$ beta blocker

patients were not on this medication, in whom "hypotension" (25.4\%), "cardiac function improved" (18.2\%) and "asthma/COPD" (16.4\%) were reported as reasons for nonprescription (Fig. 5). For ICD, 83/171 (48\%) patients with LVEF $<30 \%$ were not referred or did not have an ICD in whom, "does not qualify" (43.3\%), "not recommended by cardiologist" $(23.3 \%)$ or "poor quality of life" $(9 \%)$ were identified as reasons for non-referral(Fig. 6).

\section{DISCUSSION}

This is the first study, to our knowledge, to provide comprehensive analysis of prescription rates and dosing of evidenced-based medical therapy, rates of ICD therapy, and analysis of barriers for Canadian outpatients with LVSD. The major findings are that, for physicians referring patients for evaluation to this Canadian academic hospital centre, relatively high proportions of outpatients with LVEF $<40 \%$ 


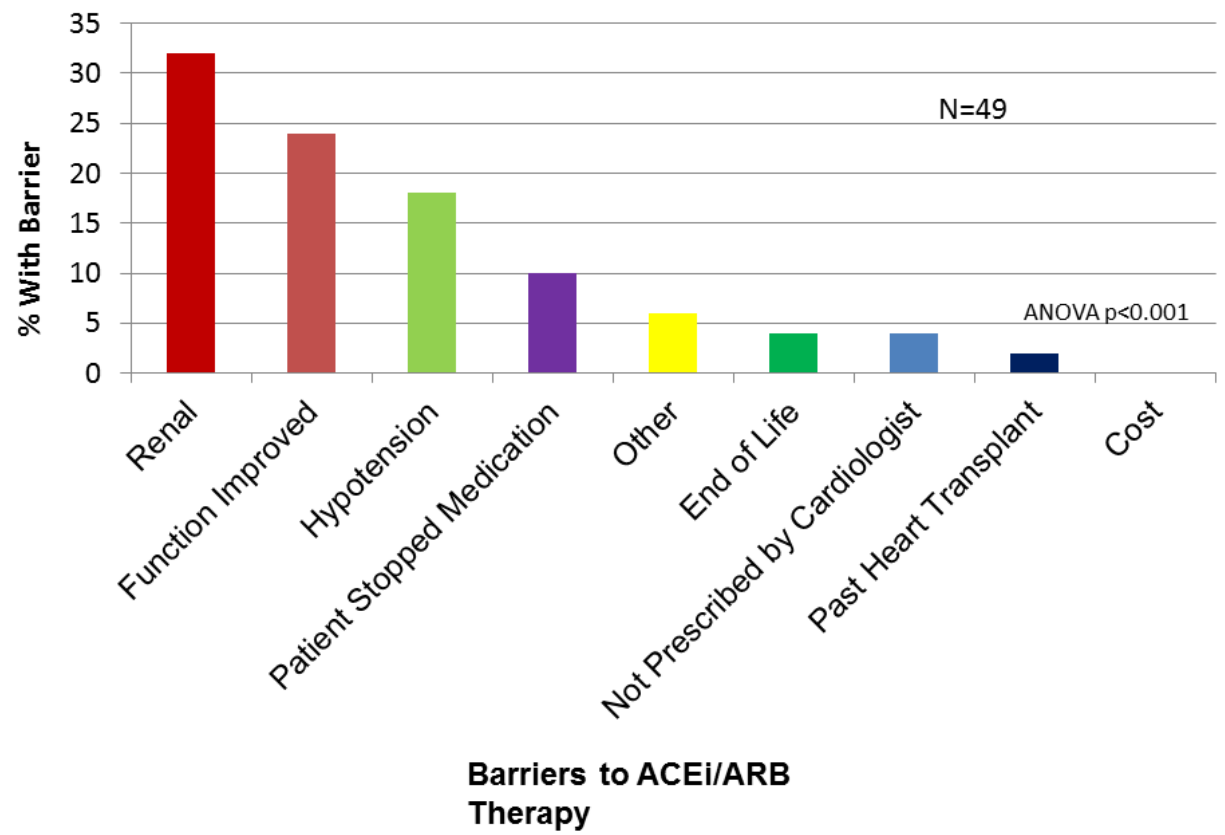

Fig. (4). Physician-Reported Barriers to ACEi/ARB Prescription. ACE=angiotensin converting enzyme. ARB=angiotensin receptor blocker.

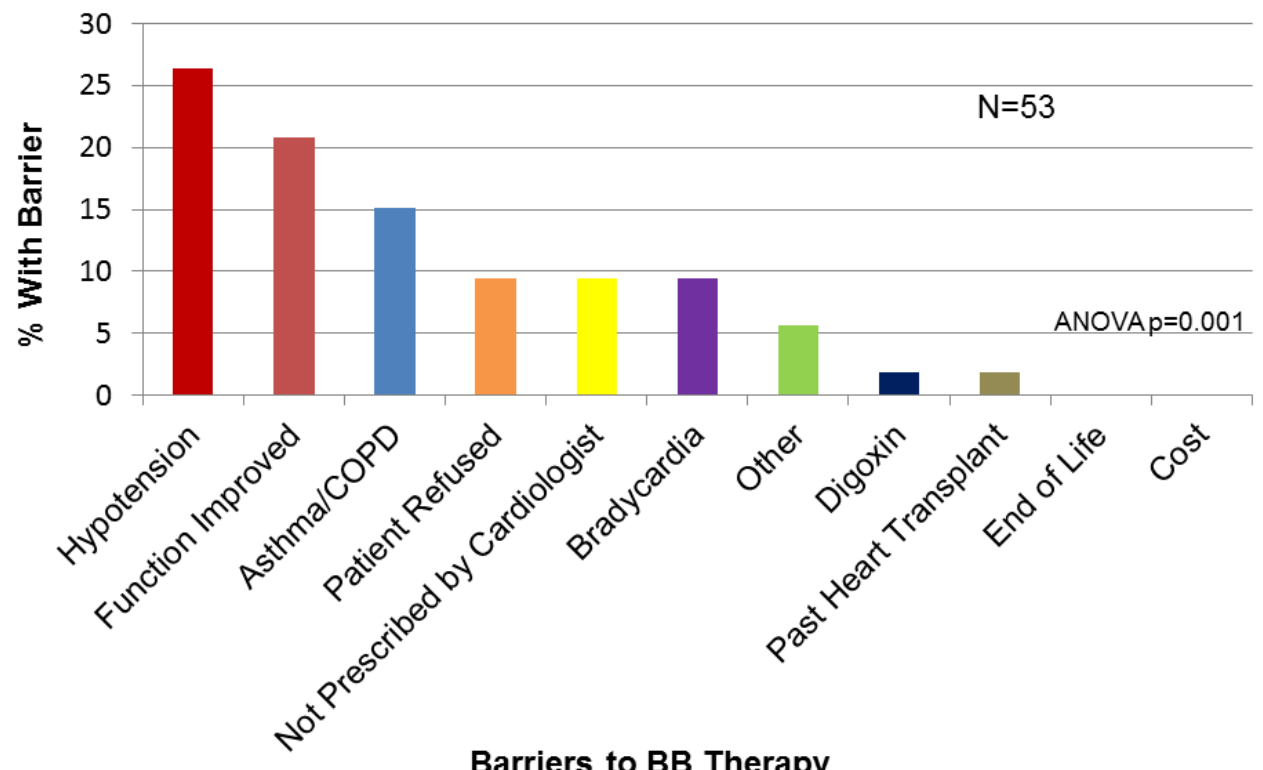

Fig. (5). Physician-Reported Barriers to BB Prescription. BB=beta-blocker.

were on evidence-based medical therapy; however, these medications were generally not at target doses. In addition, for outpatients with LVEF $<30 \%$, approximately half either have an ICD or were referred for one. Furthermore, potential barriers to prescription of evidence-based medicine and referral for ICD, as described by the referring physician, were identified.

While there are some data assessing prescription rates of evidenced-based medication in hospital inpatients with LVSD, comparative studies in outpatients are relatively few, and data in Canadian outpatients did not, to this point, exist. In a German study of 167 outpatients with LVSD (mean LVEF $33+/-6.9 \%$ ), among the placebo arm, $88.8 \%$ of the study population were prescribed an ACEi or ARB, and
$80.5 \%$ a $\mathrm{BB}$ [23]. In a survey of cardiologists in France, patients with $\mathrm{LVEF}<40 \%$ had $\mathrm{ACEi}$ prescription rates of $71 \%$, ARB of $23.6 \%$ and BB of $65 \%$ [24]. In a 2003 study from the VA system in California, among 650 patients $64 \%$ were on ACEi/ARB and $50 \%$ were on $\mathrm{BB}[26,27]$. In a study of 1613 managed care outpatients in the United States with moderate or severe LVSD in 2002, $72.3 \%$ were on ACEi and $67.9 \%$ were on $\mathrm{BB}$ [30]. In a review of the literature performed in 2000, $26 \%$ of community-dwelling HF patients were on ACEi, compared to $71 \%$ discharged from hospital with known LVSD [29]. Thus, compared to prior data from other countries, BB prescription rates may be somewhat higher among in outpatients with LVSD referred for echocardio-graphy at our academic hospital centre in 


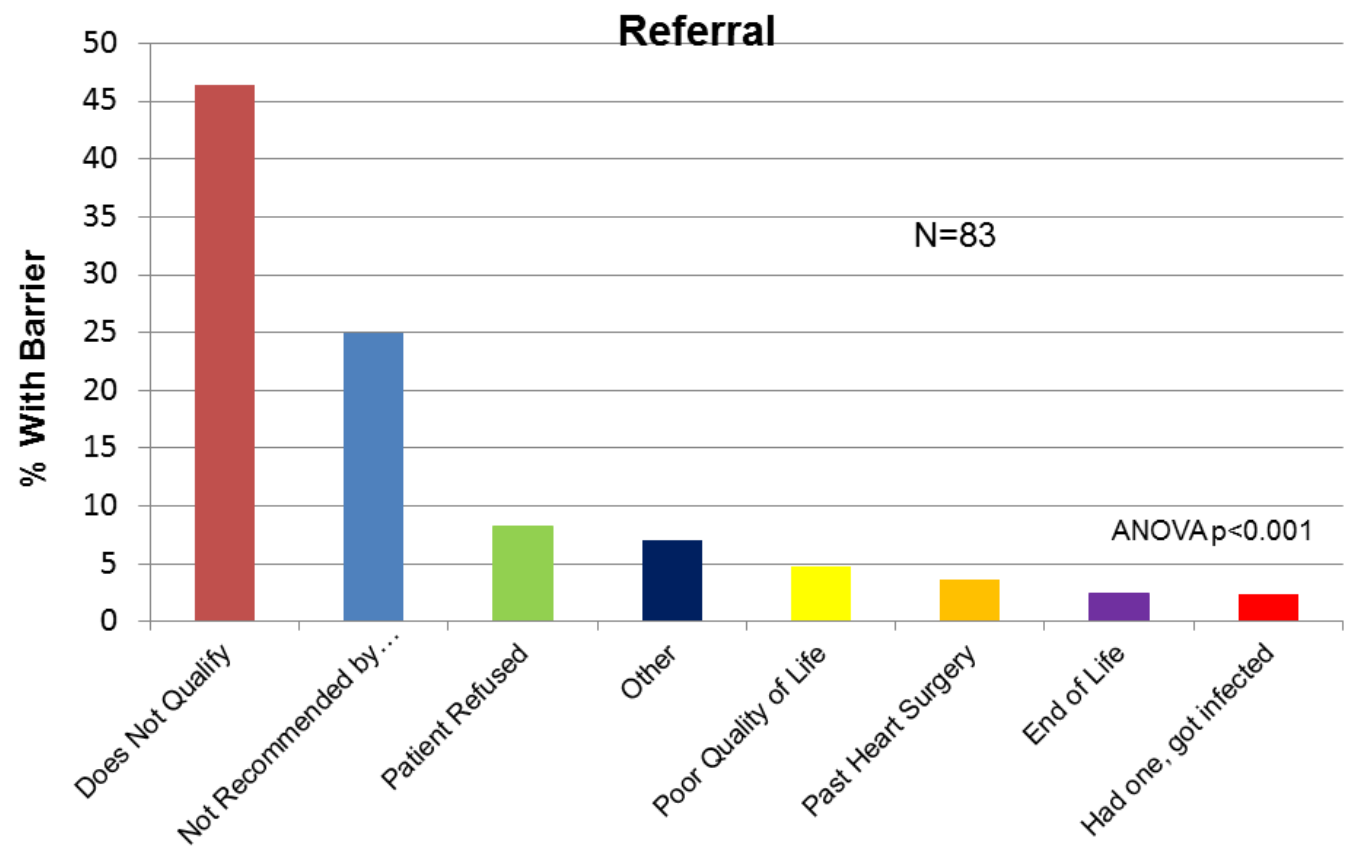

Barriers to ICD Referral

Fig. (6). Physician-Reported Barriers to ICD Referral. ICD=implantable cardiac defibrillator.

Canada, while $\mathrm{ACEi} / \mathrm{ARB}$ prescription rates appeared similar.

The proportion of patients in our study on target doses of ACEi was modest, and low for both $\mathrm{ARB}$ and $\mathrm{BB}$ when compared to target doses of HF medications as indicated in the $\mathrm{CCS}^{5}$ and ACC/AHA [6] HF guidelines. There are relatively few comparative data in prior studies on dosing of HF medications in outpatients with LVSD, and no published data, to this point, in Canadian outpatients with LVSD. In the German study, $22.7 \%$ were on target doses of ACEi, $15.2 \%$ on target doses of ACEi/ARB and $12.1 \%$ on target doses on BB [30]. The survey of cardiologists in France reported that $49 \%$ of ACEi prescriptions were at target dose, similar to $42.1 \%$ in our study, compared to $9 \%$ on target doses of ARB (15.5\% in our study) and $18 \%$ on target dose of BB (compared to $3.5 \%$ in our study) [24]. A recent report from the IMPROVE HF database showed that among 7605 $\mathrm{HF}$ patients in the US with $\mathrm{LVEF}<35 \%$, target dose treatment rates for ACEI/ARB were $36.1 \%$ and for $20.5 \%$ for BB [40]. Taken as a whole, prior data and that from our study suggest that, overall, relatively low proportions of patients with LVSD are on target doses of medications, and our data are novel as they are the first from outpatients with LVSD in Canada.

There is a paucity of previously published data on ICD referrals and reasons for non-referral in outpatients with LVSD, and none to this point from Canada. Data from the Get with the Guidelines Registry showed that among patients discharged from hospital in the United States with LVEF $<30 \%$, in-hospital implantation or planned implantation of ICD was $20 \%$ [37]. A study of 309 outpatients in heart functionclinic showed that MADIT-II criteria were met by $32 \%$ of patients and $51 \%$ met SCD-HFT criteria [39]. Our study therefore provides novel data, indicating that in the setting of physicians referring patients for echocardiography to an academic Canadian center approximately one half of outpatients with $\mathrm{LVEF}<30 \%$ either have an ICD or were referred for one.

There are often important reasons why patients with LVSD may not be on medical or device therapy, yet such data from the Canadian setting have, until now, been missing. A survey of cardiologists and family physicians caring for HF patients published in 1999 showed that family physicians were more likely to avoid prescription of ACEi in patients thought to be hypotensive or to have renal dysfunction [41]. A study from Spain assessing BB use in $100 \mathrm{HF}$ patients $>70$ years old showed that, while $84 \%$ were on $\mathrm{BB}$, this medication was discontinued in $8.4 \%$ [41]. A recent study from the UK describing a questionnaire sent to cardiologists indicated that a lack of knowledge of guidelines and lack of screening processes were the greatest barriers to uptake of ICDs in the UK [43]. A survey of 100 cardiologists and GPs in New Zealand has shown that $62 \%$ self-reported familiarity with ICD guidelines, while lack of financial resources $(88 \%)$, of local expertise $(61 \%)$, of New Zealandspecific guidelines $(51 \%)$, and the referral process $(43 \%)$ were seen as significant barriers to ICD referral by many participants [44]. Our study is unique in that it provides data on the proportion of outpatients with decreased LVEF that have an ICD or were referred for one, which to our knowledge has not been described, and also explores physician barriersto referral for ICD implantation in Canadian outpatients.

\section{LIMITATIONS}

The survey response rate, while 54\%, compares favourably to previously published survey-based data in this field(for instance, $56 \%$ in a similarly designed survey from our centre [45] and $60 \%$ in the IMPACT-RECO survey) [24]. The patients in this study had LVSD as assessed by echocardiography, not necessarily clinical HF; however, 
there were no significant differences in prescription rates between patients with and without HF symptoms. This study queried physicians on prescription of medicines and referral patterns; therefore, we did not assess patient adherence to medical therapy, by methods such as checking with pharmacies or pill counts. By design, we assessed outpatients only in this study, as it was felt that, in an academic tertiary care hospital, there would be too many confounding factors affecting prescription rates for medicines and referral for ICD, such as potentially reversible LVSD due to sepsis, arrhythmia, ischemia, renal failure, and the fact that newly diagnosed LVSD in hospital would not be on target doses of medicines, as these are generally up-titrated in the outpatient setting. Furthermore, ICD referral for primary prevention generally occurs in stable patients who are medically maximized, as opposed to acutely ill or decompensated HF patients. Prescription rates and doses, as well as referral for ICD may be higher in patients referred for echocardiography at this academic tertiary medical centre, compared to patients who would not be referred to this centre or patients in smaller communities; this question would require further study. It is important to emphasize that the concept of "target doses" may be a difficult one to attain in a given patient. While HF guidelines have indicated what target doses are to be achieved for individual ACEi, ARB and BBs, the combination of these can have cumulative effects on blood pressure, heart rate and renal function and it therefore may not be safe or desirable to achieve target doses of these medications in a given patient. It also important to point out that while bisoprolol, metoprolol succinate and carvedilol are indicated for HF, 5 patients $(2 \%)$ in this study were on atenolol and $2(0.7 \%)$ were on sotalol, medications which are not specifically indicated in HF [5]. In addition, metoprolol succinate is not available in Canada, and therefore metoprolol tartrate is instead used. Finally, since this study focused on evidence-based medical and device therapy in patients with established LV systolic dysfunction by echocardiography, we did not collect detailed cardiac risk factor data on these patients, and therefore could not assess the potential impact of diabetes and other factors on prescription rates and dosing of these therapies, a direction that would be of interest in future research.

\section{CONCLUSION}

The prescription rates of evidence-based medical therapy are relatively high in outpatients with LVSD referred for echocardiography at this Canadian academic hospital centre; however, the proportion of patients at target doses was modest for ACEi and low for ARB and BB. Approximately half of the patients who qualify for ICD by EF alone have one or were referred for ICD implantation. Important reasons for patients with LVSD not on evidence based therapy were identified. These findings are novel, as data from outpatients with LVSD in Canada has not, until now, been well defined.

\section{REFERENCES}

[1] Najafi F, Jamrozik K, Dobson AJ. Understanding the 'epidemic of heart failure': a systematic review of trends in determinants of heart failure. Eur J Heart Fail 2009; 11: 472-9. of death and hospital admissions related to acute myocardial infarction, heart failure and stroke, 1994-2004. CMAJ 2009; 180: E118-25.

[3] de Groote P, Isnard R, Clerson P, et al. Improvement in the management of chronic heart failure since the publication of the updated guidelines of the European Society of Cardiology. Eur J Heart Fail 2009; 11: 85-91.

[4] Ezekowitz JA, Rowe BH, Dryden DM, et al. Systematic review: implantable cardioverter defibrillators for adults with left ventricular systolic dysfunction. Ann Intern Med 2007; 147: 25162.

[5] Arnold JMO, Liu P, Demers C, et al. Canadian Cardiovascular Society consensus conference recommendations on heart failure 2006: diagnosis and management. Can J Cardiol 2006; 22: 23-45.

[6] Hunt SA, Abraham WT, Chin MH, et al. 2009 Focused update incorporated into the ACC/AHA 2005 Guidelines for the diagnosis and management of heart failure in adults. J Am Coll Cardiol 2009; 53: e1-90.

[7] Dickstein K, Cohen-Solal A, Filippatos G, et al. ESC guidelines for the diagnosis and treatment of acute and chronic heart failure 2008: the task force for the diagnosis and treatment of acute and chronic heart failure 2008 of the European Society of Cardiology. Eur J Heart Fail 2008; 10: 933-89.

[8] Flather MD, Yusuf S, Køber L, et al. Long-term ACE-inhibitor therapy in patients with heart failure or left-ventricular dysfunction: a systematic overview of data from individual patients. ACEInhibitor Myocardial Infarction Collaborative Group. Lancet 2000; 355: 1575-81.

[9] Shekelle PG, Rich MW, Morton SC, et al. Efficacy of angiotensinconverting enzyme inhibitors and beta-blockers in the management of left ventricular systolic dysfunction according to race, gender, and diabetic status: a meta-analysis of major clinical trials. J Am Coll Cardiol 2003; 41: 1529-38.

[10] Abdulla J, Pogue J, Abildstrøm SZ, et al. Effect of angiotensinconverting enzyme inhibition on functional class in patients with left ventricular systolic dysfunction--a meta-analysis. Eur J Heart Fail 2006; 8: 90-6.

[11] Garg R, Yusuf S. Overview of randomized trials of angiotensinconverting enzyme inhibitors on mortality and morbidity in patients with heart failure. Collaborative Group on ACE Inhibitor Trials. JAMA 1995; 273 : 1450-6.

[12] Shibata MC, Tsuyuki RT, Wiebe N. The effects of angiotensinreceptor blockers on mortality and morbidity in heart failure: a systematic review. Int J Clin Pract 2008; 62: 1397-402.

[13] Lee VC, Rhew DC, Dylan M, Badamgarav E, Braunstein GD, Weingarten SR. Meta-analysis: angiotensin-receptor blockers in chronic heart failure and high-risk acute myocardial infarction. Ann Intern Med 2004; 141: 693-704.

[14] Jong P, Demers C, McKelvie RS, Liu PP. Angiotensin receptor blockers in heart failure: meta-analysis of randomized controlled trials. J Am Coll Cardiol 2002; 39: 463-70.

[15] Brophy JM, Joseph L, Rouleau JL. Beta-blockers in congestive heart failure. A Bayesian meta-analysis. Ann Intern Med 2001; 134: 550-60.

[16] McAlister FA, Wiebe N, Ezekowitz JA, Leung AA, Armstrong PW. Meta-analysis: beta-blocker dose, heart rate reduction, and death in patients with heart failure. Ann Intern Med 2009; 150: 784-94.

[17] Fauchier L, Pierre B, de Labriolle A, Babuty D. Comparison of the beneficial effect of beta-blockers on mortality in patients with ischaemic or non-ischaemic systolic heart failure: a meta-analysis of randomised controlled trials. Eur J Heart Fail 2007; 9: 1136-9.

[18] Abdulla J, Køber L, Christensen E, Torp-Pedersen C. Effect of beta-blocker therapy on functional status in patients with heart failure--a meta-analysis. Eur J Heart Fail 2006; 8: 522-31. 
[19] Desai AS, Fang JC, Maisel WH, Baughman KL. Implantable defibrillators for the prevention of mortality in patients with nonischemic cardiomyopathy: a meta-analysis of randomized controlled trials. JAMA 2004; 292: 2874-9.

[20] Nanthakumar K, Epstein AE, Kay GN, Plumb VJ, Lee DS. Prophylactic implantable cardioverter-defibrillator therapy in patients with left ventricular systolic dysfunction: a pooled analysis of 10 primary prevention trials. J Am Coll Cardiol 2004; 44: 216672.

[21] Lee DS, Green LD, Liu PP, et al. Effectiveness of implantable defibrillators for preventing arrhythmic events and death: a metaanalysis. J Am Coll Cardiol 2003; 41: 1573-82.

[22] Ezekowitz JA, Armstrong PW, McAlister FA. Implantable cardioverter defibrillators in primary and secondary prevention: a systematic review of randomized, controlled trials. Ann Intern Med 2003; 138: 445-52.

[23] Peters-Klimm F, Müller-Tasch T, et al. Guideline adherence for pharmacotherapy of chronic systolic heart failure in general practice: a closer look on evidence-based therapy. Clin Res Cardiol 2008; 97: 244-52.

[24] de Groote P, Isnard R, Assyag P, et al. Is the gap between guidelines and clinical practice in heart failure treatment being filled? Insights from the IMPACT RECO survey. Eur J Heart Fail 2007; 9: 1205-11.

[25] Ansari M, Shlipak MG, Heidenreich PA, et al. Improving guideline adherence: a randomized trial evaluating strategies to increase betablocker use in heart failure. Circulation 2003; 107: 2799-804.

[26] Heidenreich PA, Chacko M, Goldstein MK, Atwood JE. ACE inhibitor reminders attached to echocardiography reports of patients with reduced left ventricular ejection fraction. Am J Med 2005; 118: 1034-7.

[27] Heidenreich PA, Gholami P, Sahay A, Massie B, Goldstein MK. Clinical reminders attached to echocardiography reports of patients with reduced left ventricular ejection fraction increase use of betablockers: a randomized trial. Circulation 2007; 115: 2829-34.

[28] Goff DC, Massing MW, Bertoni AG, et al. Enhancing quality of heart failure care in managed Medicare and Medicaid in North Carolina: Results of the North Carolina Achieving Cardiac Excellence (NC ACE) Project. Am Heart J 2005; 150: 717-24.

[29] Bungard TJ, McAlister FA, Johnson JA, Tsuyuki RT. Underutilisation of ACE inhibitors in patients with congestive heart failure. Drugs 2001; 61: 2021-33.

[30] Edep ME, Shah NB, Tateo IM, Massie BM. Differences between primary care physicians and cardiologists in management of congestive heart failure: relation to practice guidelines. J Am Coll Cardiol 1997; 30: 518-26.

[31] Kermani M, Dua A, Gradman AH. Underutilization and clinical benefits of angiotensin-converting enzyme inhibitors in patients with asymptomatic left ventricular dysfunction. Am J Cardiol 2000; 86: 644-8.

[32] Packer M, Poole-Wilson PA, Armstrong PW, et al. Comparative effects of low and high doses of the angiotensin-converting enzyme inhibitor, lisinopril, on morbidity and mortality in chronic heart failure. ATLAS Study Group. Circulation 1999; 100: 2312-8.

[33] Roe CM, Motheral BR, Teitelbaum F, Rich MW. Angiotensinconverting enzyme inhibitor compliance and dosing among patients with heart failure. Am Heart J 1999; 138: 818-25.

[34] Konstam MA, Neaton JD, Dickstein K, et al. Effects of high-dose versus low-dose losartan on clinical outcomes in patients with heart failure (HEAAL study): a randomised, double-blind trial. Lancet 2009; 374: 1840-8.

[35] Fonarow GC, Abraham WT, Albert NM, et al. Dosing of betablocker therapy before, during, and after hospitalization for heart failure (from organized program to initiate lifesaving treatment in hospitalized patients with heart failure). Am J Cardiol 2008; 102: 1524-9.

[36] Fowler MB, Lottes SR, Nelson JJ, et al. Beta-blocker dosing in community-based treatment of heart failure. Am Heart J 2007; 153: 1029-36.

[37] Shah B, Hernandez AF, Liang L, et al. Hospital variation and characteristics of implantable cardioverter-defibrillator use in patients with heart failure. J Am Coll Cardiol 2009; 53: 416-22.

[38] Al-Khatib SM, Sanders GD, Carlson M, et al. Preventing tomorrow's sudden cardiac death today: dissemination of effective therapies for sudden cardiac death prevention. Am Heart J 2008; 156: 613-22.

[39] Toma M, McAlister FA, Ezekowitz J, et al. Proportion of patients followed in a specialized heart failure clinic needing an implantable cardioverter defibrillator as determined by applying different trial eligibility criteria. Am J Cardiol 2006; 97: 882-5.

[40] Gheorghiade M, Albert NM, Curtis AB, et al. Medication dosing in outpatients with heart failure after implementation of a practicebased performance improvement intervention: findings from IMPROVE HF. Congest Heart Fail 2012; 18: 9-17

[41] Baker DW, Hayes RP, Massie BM, Craig CA. Variations in family physicians' and cardiologists' care for patients with heart failure. Am Heart J 1999; 138: 826-34.

[42] Yebra-Yebra M, Recio J, Arévalo-Lorido JC, Cornide-Santos L, Cerqueiro-González JM, Manzano L. [Safety and tolerance of betablocker treatment in elderly patients with heart failure]. Med Clin (Barc) 2010; 134: 141-5.

[43] Sadarmin PP, Wong KC, Rajappan K, Bashir Y, Betts TR Questionnaire survey of cardiologists' knowledge, attitudes, and guideline application of implantable cardioverter defibrillator therapy. Pacing Clin Electrophysiol 2012; 35: 672-80.

[44] McHale B, Harding SA, Lever NA, Larsen PD. A national survey of clinician's knowledge of and attitudes towards implantable cardioverter defibrillators. Europace 2009; 11: 1313-6.

[45] Nieuwlaat R, Barker L, Yang-Ki K, et al. Underuse of evidencebased warfarin dosing methods for atrial fibrillation patients. Thromb Res 2010; 125: e128-31.

This is an open access article licensed under the terms of the Creative Commons Attribution Non-Commercial License (http://creativecommons.org/licenses/ by-nc/3.0/) which permits unrestricted, non-commercial use, distribution and reproduction in any medium, provided the work is properly cited. 